\title{
Oxidative dehydrogenation of ethane under a cyclic redox scheme- Process simulations and analysis
}

\section{Authors: Vasudev Pralhad Haribal, Luke Neal, and Fanxing Li*}

Department of Chemical \& Bimolecular Engineering, North Carolina State

University, Raleigh, North Carolina 27695, United States

${ }^{*}$ To whom the correspondence should be addressed.

Telephone: +1 (919) 515-7328. Fax: +1 (919) 515-3465. E-mail: fli5@ncsu.edu. 


\begin{abstract}
Steam cracking of ethane is an energy intensive process (15-25 $\mathrm{GJ}_{\mathrm{th}} /$ tonne ethylene) involving significant coke formation and $\mathrm{CO}_{2} / \mathrm{NO}_{\mathrm{x}}$ emissions. We propose an alternative two-step redox (or chemical looping) oxidative dehydrogenation (CL-ODH) scheme where hydrogen, produced from ethane cracking, is selectively oxidized by lattice oxygen from a redox catalyst, in the first step. Regeneration of the lattice oxygen in a subsequent step heats the redox catalyst, with the sensible heat providing the thermal energy needed for the cracking reaction. The overall process provides minimal parasitic energy loss and significantly reduced $\mathrm{CO}_{2} / \mathrm{NO}_{\mathrm{x}}$ formation, while favoring ethylene formation through the removal of hydrogen. In the current study, the CL-ODH process is simulated with ASPEN Plus ${ }^{\circledR}$ using experimental data on a Mn-based redox catalyst. The CL-ODH is compared with steam cracking for an ethylene production capacity of 1 million tonne/year. Results indicate that the CL-ODH process, with $85 \%$ single-pass ethane conversion, provides $82 \%$ reduction in overall energy demand and $82 \%$ reduction in $\mathrm{CO}_{2}$ emissions. The overall downstream section consumes approximately $23.5 \%$ less energy, with $32.1 \%$ less compression work. Increase in the ethane conversion further reduces the energy demand downstream. For every tonne of ethylene, the process has $7.35 \mathrm{GJ}_{\text {th }}$ excess fuel energy whereas cracking requires an external fuel input of $1.42 \mathrm{GJ}_{\text {th }}$.
\end{abstract}

Keywords: Ethylene; cracking; ethane oxidative dehydrogenation; chemical looping; process simulations

\title{
1 Introduction
}

Ethylene is an important building block for the petrochemical industry and has the largest production volume among important base petrochemicals [1,2]. At present, ethylene is mainly used to manufacture polyethylene $(>50 \%)$, followed by vinyl chloride, ethylene oxide and ethyl benzene [3]. The global ethylene production capacity was at 143 million tonnes per annum (MTA) in 2013, a 27\% increase compared to the 2005 production capacity. A compound annual growth rate of $6 \%$ is further anticipated till 2020 and beyond [4-7].

A significant fraction of ethylene is commercially produced via high-temperature pyrolysis of hydrocarbon feedstocks in the presence of diluting steam, also known as steam cracking [3,8]. Typical feedstocks for steam cracking include those derived from crude oil, such as naphtha, gas oil, etc. and those derived from natural gas, such as ethane and propane. [6,8]. While naphtha accounts for $55 \%$ of global ethylene production capacity, ethane is the primary feedstock in regions such as the United States and Middle East. The increasing availability of shale gas in the U.S. is also making ethane cracking more favorable from a process-economic standpoint $[3,8,9]$. When ethane is used as the feedstock, the desired (overall) reaction (Reaction 1) involves decomposing ethane into ethylene and hydrogen, which is achieved via a complex network of gas phase radical reactions. 


$$
\mathrm{C}_{2} \mathrm{H}_{6} \Leftrightarrow \mathrm{C}_{2} \mathrm{H}_{4}+\mathrm{H}_{2} \quad \Delta \mathrm{H}_{298 \mathrm{~K}}=+136 \mathrm{kJmol}^{-1}
$$

In such a process, a mixed stream of ethane feed and steam is preheated to the initial cracking temperature $\left(500^{\circ}-680^{\circ} \mathrm{C}\right)$ and is fed into a high-temperature reactor $\left(750^{\circ}-875^{\circ} \mathrm{C}\right)$ to complete the cracking reaction, with residence times of 0.1-0.5 s. Key operating parameters that affect the performance of the process and the product distributions include the gas residence time, the partial pressures of the feedstock and steam, and the temperature profile in the reactor, [3,9].

Despite being practiced and optimized for more than 50 years, steam cracking has a number of limitations from chemical equilibrium, energy utilization, and environmental viewpoints. Firstly, ethane cracking is limited to a practical single-pass ethane-conversion of $67-70 \%$ and an ethylene yield of around 55\% [6] due to equilibrium limitation and coke formation. Although steam dilution reduces the rate of coke formation, steam cracking furnaces nevertheless need to be periodically shut down and regenerated with air to avoid coke build-up. The use of diluting steam increases the parasitic energy consumption whereas the need for periodic regeneration leads to an increase in the capital investment (for parallel units) and operating costs $[7,9,10]$. The total energy demand of ethane cracking ranges between 15 and $25 \mathrm{GJ} /$ tonne ethylene [8,9] which is satisfied by combustion of carbonaceous fuels such as methane. This leads to the production of 1-1.2 ton $\mathrm{CO}_{2}$ /tonne ethylene and considerable amount of $\mathrm{NO}_{\mathrm{x}}[8]$. Therefore, new technologies that overcome these limitations are highly desirable.

The oxidative dehydrogenation (ODH) of ethane, in the presence of a heterogeneous catalyst, is an attractive alternative to steam cracking. ODH has the potential to provide higher olefin yields since the formation of water as opposed to hydrogen (Reaction 2) effectively removes the equilibrium constraints on ethane conversion. Moreover, the required energy is supplied by hydrogen oxidation [11,12].

$$
\mathrm{C}_{2} \mathrm{H}_{6}+\frac{1}{2} \mathrm{O}_{2} \rightarrow \mathrm{C}_{2} \mathrm{H}_{4}+\mathrm{H}_{2} \mathrm{O} \quad \Delta \mathrm{H}_{1123 \mathrm{~K}}=-105 \mathrm{kJmol}^{-1}
$$

Reaction 2

Despite these advantages, oxygen co-feed ODH has significant limitations. The requirement of pure oxygen or oxygen-enriched air requires an air separation unit (ASU), which adds to the capital and operating costs. The high reactivity of the olefins poses another challenge in developing a suitably selective catalyst. Moreover, the oxygenate byproducts are difficult to separate [9]. The flammability of the gas mixture containing oxygen and fuels in the single step $\mathrm{ODH}$ imposes additional safety concerns. Over-oxidation of the alkanes and olefins to $\mathrm{CO}$ and $\mathrm{CO}_{2}$ can cause hot spots in the reactor and reduce product selectivity. $[8,13,14]$. The current study investigates a two-step, redox based process for ethane chemical looping-oxidative dehydrogenation (CL-ODH) in an $\mathrm{O}_{2}$-free environment. The first step involves selective oxidation of the hydrogen produced from ethane cracking using the lattice oxygen from a redox catalyst at a high temperature. The sensible heat of such catalyst provides the thermal energy needed for the cracking reaction. This is accompanied by simultaneous reduction of the catalyst. 
The reduced catalyst is subsequently regenerated (and reheated) in air to complete the redox loop. In such a CL-ODH process, the absence of gas phase oxygen a) inhibits the non-selective reaction pathways, b) reduces the explosion hazard [14-16], and c) decreases parasitic energy losses by eliminating ASU and providing tighter temperature control [17]. The overall process also provides significant reduction in $\mathrm{NO}_{\mathrm{x}}$ and $\mathrm{CO}_{2}$ emissions. However, despite of the advantages of CL-ODH over both steam cracking and oxygen co-feed experiments, this novel process, has not been analyzed to date.

In a previous work, we have reported a highly effective, alkali doped $\mathrm{MnO}_{\mathrm{x}}-\mathrm{MgO}$ redox catalyst for the abovementioned CL-ODH scheme [17,18]. High ethane conversion and ethylene selectivity as well as satisfactory redox stability and oxygen carrying capacity are achieved using such a redox catalyst. The current study investigates the performance of the CL-ODH process by conducting comprehensive process simulation and analyses based upon preliminary experimental yield data from an alkali doped $\mathrm{MnO}_{\mathrm{x}}-\mathrm{MgO}$. Single-pass ethane conversions of $66 \%, 85 \%$ and 90\% are analyzed and the results are compared with a state-of-the-art ethane steam cracking process. Sensitivity analyses are performed on key process parameters such as ethane conversion, product distribution, unit-wise and total energy requirement of the process. Using ASPEN Plus ${ }^{\circledR}$, the reactor and process conditions are optimized and the potential advantages of the redox-based ODH process are also validated based on comprehensive process analyses. For a single-pass ethane conversion of $85 \%$, as compared to the steam cracking process, the overall downstream section energy demands of the $\mathrm{ODH}$ case are shown to drop by $23.5 \%$ with $32.1 \%$ less compression work. This leads to $82 \%$ drop in the overall energy demand and $82 \%$ reduction in $\mathrm{CO}_{2}$ emissions. The energy demand for $\mathrm{ODH}$ decreases with increasing single-pass ethane conversion.

\section{Process descriptions}

Figure 1a is a simplified process flow diagram of a state-of-the-art ethane steam cracking process. Pre-heated ethane is thermally cracked in the presence of steam, which functions as a diluent for higher conversions and as a coke-retardant. The feed mixture is passed through the tubes of up to twelve cracker furnaces, which are heated by combustion of fuels to provide considerable heat input at high temperatures $\left(\sim 1,000^{\circ} \mathrm{C}\right)$. The hot product stream from the furnace, at approximately $850^{\circ} \mathrm{C}$, is first rapidly cooled to $300^{\circ}-400^{\circ} \mathrm{C}$ using transfer line heat exchangers to avoid further cracking and preserve the composition. It is further quenched to near ambient temperature using water or oil [3,6]. The stream is then compressed to a pressure of around 40 bar with a multi-stage compressor. Drying and acid gas removal units are located at the intermediate compressor stages. The drying unit consists of an adsorption column of molecular sieves and precedes the acid gas removal units to avoid formation of hydrates [6]. The stream is then caustic washed to remove the acid gases such as $\mathrm{CO}_{2}$. 
The compression stages are followed by a train of distillation columns which sequentially separate the light components from the heavy fraction, yielding high purity ethylene. The sequence begins with the removal of methane and lighter components, primarily hydrogen, from higher molecular mass components, using a demethanizer. The bottom product is routed to a deethanizer column where acetylene, ethane, and ethylene are separated and $\mathrm{C} 3+$ components exit as the bottom product. The overhead mixture is subsequently treated with hydrogen to remove acetylene and then fractionated in the $\mathrm{C} 2$-splitter to give ethylene product and ethanerecycle. The bottom product from the deethanizer is depropanized to separate $\mathrm{C} 4+$ components. Depropanizer bottoms are sent to a debutanizer for separation of the $\mathrm{C} 4$ materials, raw pyrolysis gasoline, C5 materials and aromatics [6]. In the C3-splitter, propylene is recovered as a valuable product and propane is recycled. Traditionally, the front-end demethanizer process sequence was used in cracking process. In alternative configurations, a front-end deethanizer or depropanizer can be used. While the front-end deethanizer option can be advantageous in certain cases [6], it is not investigated in the current study for the purpose of direct comparison with the ODH process.

The ethane ODH process is depicted in Figure1b. The major difference from steam cracking is the absence of the energy-intensive furnaces, which are replaced by a reactor-regenerator configuration. The hydrocarbon and $\mathrm{CO}_{\mathrm{x}}$ yields used in the current work are based upon experimental results of an alkali doped $\mathrm{Mn}-\mathrm{Mg}$ oxide similar to that reported in previous work $[17,18]$. As this system involves mixed oxides [18] that are not available in the ASPEN Plus ${ }^{\circledR}$ database, the system is simplified to a $\mathrm{MgO}$ supported $\mathrm{MnO}_{\mathrm{x}} \cdot \mathrm{Mn}_{3} \mathrm{O}_{4}$ (Mn at $8 / 3+$ average valence state) is used as the simulated oxygen carrier phase, which donates its lattice oxygen during the ODH reaction. Meanwhile, the Mn cation is reduced to a 2+ average valence state $(\mathrm{MnO})$, as shown in Reaction 3. The reaction involves the combustion of hydrogen to water. The reduced redox catalyst, (also known as an oxygen carrier), is subsequently regenerated using air in the regenerator, following a highly exothermic Reaction 4. While slow reduction kinetics [19] and propensity for deep oxidation [20,21] would make undoped $\mathrm{Mn}_{3} \mathrm{O}_{4}$ unsuitable as a practical oxygen carrier, the thermodynamics of $\mathrm{MnO}_{\mathrm{x}} / \mathrm{MgO}$ give satisfactory simulation results. Comparing the ASPEN Plus ${ }^{\circledR}$ database values for such a surrogate catalyst with our experimental data indicates that the surrogate catalyst exhibits similar heat of reaction and heat capacity values when compared to actual redox catalysts. In the current study, the reducer is operated at $850^{\circ} \mathrm{C}$ and the regenerator at $950^{\circ} \mathrm{C}$, both at near-atmospheric pressure. The re-oxidized redox catalyst particles are recirculated to the reducer to complete the redox loop. It is noted that the redox catalyst not only provides its lattice oxygen but also carries heat required for ODH reactions. Unconverted ethane and propane from the downstream separation block are recirculated to achieve higher overall conversion. Heat loss for the redox process is assumed to be $1 \%$ of the total thermal output whereas redox catalyst loss is assumed to be negligible. The hot, oxygendepleted air from the regenerator is used to generate high pressure steam. The gaseous output from the reducer is treated through a chain of downstream separation units which are nearly identical to the steam cracking. All of the ethane and propane are recycled to the reducer, the 
heat requirements of which are met entirely via the heat stored in the re-oxidized solids, owing to their high heat capacity and suitable temperature difference $(\Delta \mathrm{T})$ between the reducer and regenerator. The heat needed by the cracking furnaces represents a major energy requirement for steam cracking. In contrast, exothermicity of the regenerator is used to compensate the heat needed for the ODH reactor, thereby lowering the upstream energy demand in ODH. In the following sections, the overall energy requirement for the ODH process is evaluated and compared with that of ethane cracking.

$$
\begin{array}{llr}
\mathrm{C}_{2} \mathrm{H}_{6}+\mathrm{Mn}_{3} \mathrm{O}_{4} \rightarrow \mathrm{C}_{2} \mathrm{H}_{4}+3 \mathrm{MnO}+\mathrm{H}_{2} \mathrm{O} & \Delta \mathrm{H}_{1123 \mathrm{~K}}=+118 \mathrm{~kJ} / \mathrm{mol} & \text { Reaction } 3 \\
3 \mathrm{MnO}+\frac{1}{2} \mathrm{O}_{2} \rightarrow \mathrm{Mn}_{3} \mathrm{O}_{4} & \Delta H_{1123 \mathrm{~K}}=-223 \mathrm{~kJ} / \mathrm{mol} & \text { Reaction } 4
\end{array}
$$

\section{Simulation assumptions}

ASPEN Plus ${ }^{\circledR}$ simulator [22] is used to determine the process performance of ethane CL-ODH and compare it with steam cracking. The processes are simulated for an ethylene production capacity of 1 million tonnes per year. The cracking process (Case I) and the ODH reference case (Case II) with an ethane single-pass conversion of $85 \%$ are simulated. ASPEN Plus ${ }^{\circledR}$ modules, property methods, and physical property databanks are summarized in Table 1. The carbon yields for the various processes are listed in Table 2. These are based on the experimental results as given in previous work $[17,18]$. Although small amount of $\mathrm{CO}_{\mathrm{x}}$ from coke burning can be observed during redox catalyst regeneration, the yield is negligible, and is thus excluded from the simulation. The yields assumed for propane (recycled) cracking [6] as well as for propane ODH are given in the supplementary document. The drying unit is modeled as a flash column, where almost all of the water is condensed, and the acid gas removal (AGR) unit is placed at the exit of the compressor. A Sep block is used to simulate the AGR with the energy consumption accounted for. The solids used in the simulation include $\mathrm{Mn}_{3} \mathrm{O}_{4}$ and $\mathrm{MnO}$ with $\mathrm{MgO}$ added as an inert to mimic the actual catalyst [18]. The key operating assumptions and parameters used in the simulations are listed in Table 3.

\section{Process modeling}

The feed is considered as a mixture of $95 \%$ ethane and $2.5 \%$ of propane and methane, by volume, at a preheated temperature of $650^{\circ} \mathrm{C}$. Such a gaseous mixture is also known as ethane-mix and is normally used as a feedstock in industrial practice [23]. In the case of a cracking furnace, steam is also fed at $650^{\circ} \mathrm{C}$. As mentioned earlier, $\mathrm{Mn}_{3} \mathrm{O}_{4}$ is used as the oxygen carrier in the ODH case. In the process simulation, the $\mathrm{Mn}_{3} \mathrm{O}_{4}$ particles are initially fed into the reducer, from the exit of which they are transported to the regenerator. There is a $\Delta \mathrm{T}$ of $100^{\circ} \mathrm{C}$, between the reducer and regenerator, with the regenerator being higher at $950^{\circ} \mathrm{C}$. In the regenerator, the reduced oxygen 
carrier is fully oxidized in $10 \%$ excess air, preheated to $650^{\circ} \mathrm{C}$, via Reaction 3 , prior to the recirculation to the reducer for another redox loop.

The product gases in both the cases are cooled to a temperature of $30^{\circ} \mathrm{C}$, to avoid further cracking. Heat released from the rapid cooling process is assumed to be completely utilized to generate steam and to preheat the ethane and air feeds. The exothermicity of the regenerator can also produce low pressure steam and reduce the upstream energy demand. The cooled gases are flashed to remove the water from the stream. In the present model, this flash column functions as a drying unit and is placed before the compressor, rather than between the initial stages of compression. The dry stream is then compressed to a pressure of $42 \mathrm{~atm}$ [6], using a 4-stage isentropic compressor, with the exit stream at $25^{\circ} \mathrm{C}$. $\mathrm{No}_{2} \mathrm{~S}$ is assumed to be in the product stream, with $\mathrm{CO}_{2}$ being the primary component of acid gas. Negligible energy consumption is assumed for the caustic wash. For ODH, where there is substantially more $\mathrm{CO}_{2}$ in the product stream, an amine scrubbing process is assumed with an energy consumption of $0.11 \mathrm{MW}$ hr/tonne $\mathrm{CO}_{2}$ [24]. The operating conditions of the downstream columns, for the cracking process, are listed in Table 4 [25]. The compressed stream is cooled to $-100^{\circ} \mathrm{C}$ which leads to the separation of hydrogen and $\mathrm{CO}$ prior to methane removal. The refrigeration requires a high duty and removes $97 \%$ of the hydrogen and $63 \%$ of the CO, reducing the load on the demethanizer. The ethane and propane obtained from the $\mathrm{C} 2$ and $\mathrm{C} 3$-splitters respectively, are completely recycled to the reducer at $650^{\circ} \mathrm{C}$. The reflux ratio for each column is fixed as twice that of the $\mathrm{R}_{\text {min }}$. For direct comparison, the $\mathrm{C} 2$-splitters in both cases are modeled with the same number of stages and with the same recovery. The concentration of acetylene in the final, polymer-grade ethylene stream needs to be less than $5 \mathrm{ppm}$. A deacetylenizer is used to hydrogenate the acetylene in the overhead stream of deethanizer. [5][9] Purified hydrogen for acetylene hydrogenation is obtained through pressure swing adsorption (PSA). A 80\% hydrogen recovery is assumed, with the purity being $99 \%$ and a pressure drop of 1 bar [26]. Operating conditions of the deacetylenizer are based on the study of an industrial cracking unit (Table S3 of the supplementary document) [27].

Since the process consumes different forms of energy such as thermal energy, steam, and electricity, it is helpful to convert them into a same thermal basis for process comparison. An $\mathrm{HHV}$ efficiency of $85 \%$ is considered for the thermal to steam energy conversion, whereas $40 \%$ (HHV) efficiency is considered for thermal to mechanical energy conversion [8]. Using the condenser and reboiler duties of the columns, as calculated by ASPEN Plus ${ }^{\circledR}$, the power needed for refrigeration is calculated using the power-temperature graph as given in literature [28]. The refrigerants chosen for each unit are listed in Table 5. 


\section{$5 \quad$ Results and discussion}

\subsection{Reactor product distributions}

The feed and exit gas compositions of the two cases are presented in Table 6. For ethane cracking, a steam dilution of $0.3 \mathrm{~kg} / \mathrm{kg}$ fresh feed, is assumed [6]. In the ODH case, conversion of $\mathrm{H}_{2}$ to $\mathrm{H}_{2} \mathrm{O}$ is fixed at $71 \%$, for thermal sufficiency. The energy demand for the columns is accounted for by condenser refrigeration, based on the simulated duty. For the same final ethylene throughput, there is a 64\% drop in the amount of hydrogen at the reactor output for ODH when compared to cracking. As a result, the total molar output is reduced by $15 \%$. Owing to higher $\mathrm{CO}_{\mathrm{x}}$ and $\mathrm{C} 3+$ selectivity, the $\mathrm{ODH}$ case requires $11.4 \%$ more fresh ethane feed. Meanwhile, $\mathrm{ODH}$ leads to a $76 \%$ increase in the molar output of $\mathrm{C} 2+$ components from the reactor. Due to the $63 \%$ drop in the amount of unreacted ethane flowing through the system, the total mass of the product stream is higher in the case of steam cracking. As a part of the analysis, the High Value Products (HVPs) are considered which include the C2+ olefins, C5 compounds and aromatics.

\subsection{Energy distribution}

ASPEN Plus ${ }^{\circledR}$ simulation of the ethane cracking process indicates an energy consumption of 15.2 GJ/tonne ethylene. This is in agreement with the study of Ren et.al [8] which states 15-25 GJ/tonne ethylene. Depending on the temperatures in the condensers of the columns, the refrigerants are chosen as shown in Table 5 and the corresponding refrigeration power can be calculated [28]. For the cracking process, $61 \%$ of the upstream energy is required to suffice the endothermicity of the furnace, as shown in Figure 2. Quenching of the hot gases generates high pressure steam and recovers additional energy. The compression step requires $47 \%$ of the downstream energy, while the refrigeration for the demethanizer feed, and the $\mathrm{C} 2$ splitter demand $29 \%$ and $14 \%$ respectively. The C2-splitter is the most energy-intensive separation column. Figure 2a shows the section wise energy distribution in cracking process and the ODH reference case (overall and downstream). The energy distribution for steam cracking is presented in Table 7.

\subsection{Process comparisons}

Unlike steam cracking which requires significant amount of energy for the endothermic cracking reactions and steam generation, the CL-ODH case is operated based on cyclic redox reactions (Reactions 3 and 4) which are net exothermic. The regenerator replenishes the oxygen in the carrier via the highly exothermic Reaction 4 . The heat loss in the reactors is assumed to be $1 \%$ and is accounted for in the regenerator output. The oxygen-lean hot air leaving the regenerator is used to generate high pressure steam, and is counted as available upstream energy in the ODH case. As a result, the upstream and overall energy requirements for ODH are reduced significantly. The exothermicity of the regenerator and the absence of steam further reduce the upstream energy (thermal) demand and take the upstream section from $218.9 \mathrm{MW}_{\text {th }}$ net endothermic for cracking to $115.2 \mathrm{MW}_{\text {th }}$ net exothermic for the $\mathrm{ODH}$ case, as shown in Table 7. 
This accounts for the most significant reduction in energy demand in ODH compared to steam cracking.

The main downstream energy savings in the ODH case are in the compression section, where there is a $32.1 \%$ drop, due to a corresponding drop in the total moles of the product gases, on a dry basis. The overall drop in the downstream energy requirement is $23.5 \%$. An overall drop in the total mass flowing downstream reduces the energy for refrigeration prior to the demethanizer. This reflects in the reduced refrigeration duty needed to cool the feed to the demethanizer. The small amounts of $\mathrm{CO}$ and $\mathrm{CO}_{2}$ present in cracking product case do not add significant energy of separation. The amine scrubbing unit is likely to be required for the ODH case, due to the high $\mathrm{CO}_{2}$ content of 3.2 vol\% (dry basis). Overall, $0.11 \mathrm{MW}-\mathrm{hr}$ of work/tonne of $\mathrm{CO}_{2}$ captured is needed for the process [24]. For the simulated plant capacity, this accounts for $1.36 \mathrm{MW}$ (electric)-demand for the $\mathrm{ODH}$ case, which assumes a $100 \% \mathrm{CO}_{2}$ removal. There is $3.2 \mathrm{vol} \%$ of $\mathrm{CO}$ present in the outlet for the ODH case as well, on a dry basis, compared to 300-400 ppm for the cracker output. The PSA unit adds to the energy expense downstream, contributing an energy requirement of $2.2 \mathrm{~kW}-\mathrm{hr}$ (electric)/ $/ \mathrm{kg} \mathrm{H}_{2}$ separated [26]. Based on the assumptions of the PSA mentioned earlier, this sums up to a requirement of 0.7 and $0.2 \mathrm{MW}_{\text {th }}$ (thermal) energy for the cracking and ODH case respectively, owing to lesser amount of hydrogen to be separated in the PSA for the ODH case. Overall, the ODH case provides an $82 \%$ drop in the overall energy demand of the plant, compared to cracking, for a 1 million tonne capacity of ethylene per year.

The deacetylenizer in both cases operates at high pressures ( $\sim 35$ bar) and temperatures of $50^{\circ}$ $70^{\circ} \mathrm{C}$ [27]. The reactant gas from the top of a deethanizer is at a very low temperature $\left(-47^{\circ} \mathrm{C}\right)$. For $\mathrm{ODH}$, the pre-demethanization refrigeration removes $63 \%$ of the $\mathrm{CO}$ with the remaining passing on to the demethanizer (DM). Less mass is fed to the DM in the ODH case. The condenser duty of the deethanizer (DE) is reduced due to a considerable drop $(\sim 60 \%)$ in the amount of ethane flowing into the DE, owing to the high single-pass ethane conversions. The ODH case showed a 5\% drop in the condenser duty. As shown in Table 6, the amount of propane+propylene in the ODH case is twice of that in cracking. As a result, the cooling duty of the ODH-C3 splitter is twice that of cracking. Key comparisons between the energy demands are shown in Figures 3 and 4.

\subsection{Emission comparisons}

The fuel gases produced during the process, which include $\mathrm{CO}, \mathrm{CH}_{4}$ and $\mathrm{H}_{2}$, can be burned to (partially) satisfy the energy requirements. In Figure 5 it is assumed that all of the fuels are combusted to extract their energy value. Using the $\Delta \mathrm{H}_{\text {reaction }}$ as given in Table 8 and the available fuel, as given by ASPEN Plus ${ }^{\circledR}$, the total available energy from the fuels is calculated. Figure 5 compares the available energy from the fuels, energy demand from the process, and the net energy production/consumption. For the $\mathrm{ODH}$ case, there is $7.35 \mathrm{GJ}_{\text {th }}$ excess as compared to the cracking process, which has a $1.42 \mathrm{GJ}_{\text {th }}$ deficit for every tonne of ethylene produced. 
However, for the same amount of ethylene, the ODH case requires more ethane in the feed than cracking, which translates to an energy-penalty for the system. On the other hand, it also gains an energy-credit in the form of $\mathrm{C} 3+$ compounds. If these are taken into account, using the lower heating values (LHV) of ethane and C3+ compounds [29], the ODH case has an overall energypenalty of $3 \mathrm{GJ}_{\mathrm{th}}$ for every tonne of ethylene produced.

In the case of cracking, negligible amount of $\mathrm{CO}_{2}$ is present in the product gases. Based on the total energy demand and available $\mathrm{CO}$ and $\mathrm{CH}_{4}$, as given in Table 8 and Figure 5, 2176.3 $\mathrm{kmol} / \mathrm{hr}$ of $\mathrm{CH}_{4}$ is required to meet the demand of $483.4 \mathrm{MW}_{\text {th. }}$ In the case of the $\mathrm{ODH}$, after burning the $\mathrm{CO}$, combustion of $292.7 \mathrm{kmol} / \mathrm{hr}$ of $\mathrm{CH}_{4}$ is required for energy consumption. By assuming an emission factor of $60 \mathrm{~kg} \mathrm{CO} / \mathrm{GJ}$ electricity, the cracking process leads to an emission of 1.2 tonne $\mathrm{CO}_{2}$ /tonne ethylene [8] as compared to 0.22 tonne $\mathrm{CO}_{2}$ /tonne ethylene for the $\mathrm{ODH}$ case. Therefore $\mathrm{CL}-\mathrm{ODH}$ provides $82 \%$ drop in $\mathrm{CO}_{2}$ emissions. Unlike cracking which generates significant amount of $\mathrm{NO}_{\mathrm{x}}$ from fuel burning [30], ODH case has significantly lower $\mathrm{NO}_{\mathrm{x}}$ emissions as well.

\section{Sensitivity analysis}

\subsection{Ethylene yield}

The effect of ethane single-pass conversion is also studied. Two additional cases are considered for the redox ODH process; one at 66\% single-pass ethane conversion (similar carbon yield as cracking) and one at $90 \%$. The carbon yields of the various products are listed in Table 9. The exit gas composition and the energy distribution and demand-reduction, relative to the reference and cracking case, are analyzed.

As shown in Table 10, with an increase in the ethane conversion, there is a corresponding increase in the amount of heavier hydrocarbons $(\mathrm{C} 3+)$ produced. The total molar flow-rate on a dry basis decreases at higher conversions, which corresponds to a drop in the compression work. As the heavier hydrocarbon content increases, the mass throughput increases.

The effect of the change in the ethane conversion on the section wise and overall energy (thermal) demand can be seen in Figures 6 and 7. With an increase in the ethylene yield, the overall energy demand of the process drops from 154 to 87 to $54 \mathrm{MW}_{\text {th }}$ as the single pass ethane conversion increases from $66 \%$ to $85 \%$ to $90 \%$. The available energy from the regenerator, quench, and the hot exit-air, increases with an increase in the single-pass ethane conversion, which thereby reduces the overall energy demand. A better way of comparison among the processes is by using the output of the HVPs, as shown in Figures 8 and 9, where each value is expressed per tonne of HVP. From Figure 9, it can be seen that as the ethane single-pass conversion increases from $66 \%$ to $90 \%$, the $\mathrm{CO}_{2}$ emissions decrease from 0.31 to 0.17 tonne $\mathrm{CO}_{2} /$ tonne ethylene. This translates to 0.27 and 0.13 tonne $\mathrm{CO}_{2} /$ tonne HVP respectively. With respect to the cracking case, which 
emits 1.2 tonne $\mathrm{CO}_{2} /$ tonne ethylene [8], the increase in ethane conversion from $66 \%$ to $90 \%$ leads to a reduction in $\mathrm{CO}_{2}$ emissions from $74 \%$ to $87 \%$.

\subsection{Effect of pressure drop}

Solid circulation in the CL-ODH process leads to a pressure drop, which requires additional compression work [27]. The following analysis calculates the amount of work needed to negate the pressure drop in the ODH reactors. Pressure drops of 0.1, 0.2, 0.3 and 0.4 atm are studied and the corresponding energy requirements are presented in Figure 10. Although the reactor pressure drop related to solids circulation can increase the overall energy demand for ODH, the energy related to solids circulation is anticipated to be small. Even with a conservative assumption of $0.4 \mathrm{~atm}$ pressure drop for each reactor, the energy loss adds up to $0.43 \mathrm{GJ} /$ tonne HVP. Under such a scenario, $\mathrm{ODH}$ is still $79.2 \%$ less energy intensive than cracking.

\subsection{Regenerator air requirements}

The effect of increasing the amount of air in the regenerator is studied in this section for the $\mathrm{ODH}$ reference case. As shown in Figure 11, excess air in the regenerator decreases the exothermicity of the regenerator and demands more heat input to preheat the air to $650^{\circ} \mathrm{C}$, but there is more available heat from the hot exit air. Overall, there is a decrease in the net available energy from the regenerator section, with an increase in the amount of air. Excess air would result in unnecessary energy expenditure to heat the input air and then extract heat from it at the outlet. The overall energy demand $\left(\mathrm{MW}_{\mathrm{th}}\right)$ of the process increases with an increase in the amount of air fed. This is shown in Figure 11. The optimum is likely to be $\leq 20 \%$ excess air, which can be achievable using the Mn-based redox catalysts.

\section{Conclusion}

The present study compares a redox ethane ODH process with the traditional steam cracking process. Unlike the endothermic steam cracking process, redox ODH is net exothermic due to selective combustion of $\mathrm{H}_{2}$ byproduct. The use of $\mathrm{Mn}$ based redox catalyst under a cyclic redox scheme eliminates the needs for air separation. The exothermicity of the regenerator and the available energy from the hot regenerator exhaust enable the upstream section of the ODH process to be 115.2 $\mathrm{MW}_{\text {th }}$ exothermic as compared to $218.9 \mathrm{MW}_{\text {th }}$ net endothermic for a cracker. For the same ethylene throughput, ethane ODH with $85 \%$ single-pass ethane conversion results in $32 \%$ less molar flow. This translates to significant drop in compression work for downstream separations. Overall, the ODH reference case consumes $82 \%$ less energy over cracking, i.e. steam cracking has an energy demand of $15.2 \mathrm{GJ} /$ tonne ethylene whereas the ODH process demands 2.7 GJ/tonne ethylene. By burning all the fuel produced in the process $\left(\mathrm{CO}, \mathrm{H}_{2}\right.$ and $\mathrm{CH}_{4}$ ), the $\mathrm{ODH}$ case has $7.35 \mathrm{GJ}_{\text {th }}$ excess fuel energy as compared to the cracking process, which has a $1.42 \mathrm{GJ}_{\text {th }}$ deficit for every tonne of ethylene produced. The redox ODH process also provides $82 \%$ reduction in the $\mathrm{CO}_{2}$ and $\mathrm{NO}_{x}$ emissions over steam cracking. Increase in singlepass ethane conversion for redox $\mathrm{ODH}$ can lead to further reduction in energy demand and less 
$\mathrm{CO}_{2} / \mathrm{NO}_{\mathrm{x}}$ emissions. The energy requirements for solids circulation in redox ODH lead to an energy-penalty of less than $0.6 \mathrm{GJ}_{\text {th }}$ per tonne of ethylene produced. To summarize, redox ODH represents a potentially attractive option for ethylene production with significantly reduced pollutant emissions and energy consumptions.

\section{Acknowledgement}

We acknowledge the funding support from Advanced Research Project Agency-Energy (ARPAE) of the US Department of Energy (Grant DE-AR0000327), Kenan Institute, and EcoCatalytic Technologies LLC.

\section{References:}

[1] Global Ethylene Market: Trends \& Opportunities (2015-2019), Res. Mark. (2015). http://www.researchandmarkets.com/research/llnwzw/global_ethylene (accessed October 13, 2015).

[2] S. Seifzadeh Haghighi, M.R. Rahimpour, S. Raeissi, O. Dehghani, Investigation of ethylene production in naphtha thermal cracking plant in presence of steam and carbon dioxide, Chem. Eng. J. 228 (2013) 1158-1167. doi:10.1016/j.cej.2013.05.048.

[3] J.A. Moulijn, M. Makkee, A.E. Van Diepen, Chemical process technology, John Wiley \& Sons, 2013.

[4] Forecast of Global Supply and Demand Trends for Petrochemical Products for the period 2006 to 2019, Ministry of Economy, Trade and Industry (METI), Japan, 2015. http://www.meti.go.jp/english/press/2015/0612_03.html (accessed October 13, 2015).

[5] Brelsford, Robert, Rising demand, low-cost feed spur ethylene capacity growth, Oil Gas J. (2014).

[6] H. Zimmermann, R. Walzl, Ethylene, in: Ullmanns Encycl. Ind. Chem., Wiley \& Sons, 2009.

[7] Global Ethylene (Polyethylene, Ethylene Oxide, Ethylene Benzene, Ethylene Dichloride, and Others) Market Industry Analysis 2014-2020, Res. Mark. (2015).

http://www.prnewswire.com/news-releases/global-ethylene-polyethylene-ethylene-oxideethylene-benzene-ethylene-dichloride-and-others-market-industry-analysis-2014-2020300115428.html (accessed October 13, 2015).

[8] T. Ren, M. Patel, K. Blok, Olefins from conventional and heavy feedstocks: Energy use in steam cracking and alternative processes, Energy. 31 (2006) 425-451. doi:10.1016/j.energy.2005.04.001.

[9] C.A. Gärtner, A.C. van Veen, J.A. Lercher, Oxidative Dehydrogenation of Ethane: Common Principles and Mechanistic Aspects, ChemCatChem. 5 (2013) 3196-3217. doi:10.1002/cctc.201200966. 
[10] F. Cavani, N. Ballarini, A. Cericola, Oxidative dehydrogenation of ethane and propane: How far from commercial implementation?, Catal. Today. 127 (2007) 113-131. doi:10.1016/j.cattod.2007.05.009.

[11] I.A. Bakare, S.A. Mohamed, S. Al-Ghamdi, S.A. Razzak, M.M. Hossain, H.I. de Lasa, Fluidized bed ODH of ethane to ethylene over $\mathrm{VOx}-\mathrm{MoOx} / \gamma-\mathrm{Al} 2 \mathrm{O} 3$ catalyst: Desorption kinetics and catalytic activity, Chem. Eng. J. 278 (2015) 207-216. doi:10.1016/j.cej.2014.09.114.

[12] M.L. Rodríguez, D.E. Ardissone, E. López, M.N. Pedernera, D.O. Borio, Reactor Designs for Ethylene Production via Ethane Oxidative Dehydrogenation: Comparison of Performance, Ind. Eng. Chem. Res. 50 (2011) 2690-2697. doi:10.1021/ie100738q.

[13] M.M. Bhasin, J.H. McCain, B.V. Vora, T. Imai, P.R. Pujado, Dehydrogenation and oxydehydrogenation of paraffins to olefins, Appl. Catal. Gen. 221 (2001) 397-419.

[14] E.A. de Graaf, G. Rothenberg, P.J. Kooyman, A. Andreini, A. Bliek, Pt0.02Sn0.003Mg0.06 on $\gamma$-alumina: a stable catalyst for oxidative dehydrogenation of ethane, Appl. Catal. Gen. 278 (2005) 187-194. doi:10.1016/j.apcata.2004.07.053.

[15] N. Ballarini, F. Cavani, A. Cericola, C. Cortelli, M. Ferrari, F. Trifirò, G. Capannelli, A. Comite, R. Catani, U. Cornaro, Supported vanadium oxide-based catalysts for the oxidehydrogenation of propane under cyclic conditions, Catal. Today. 91-92 (2004) 99104. doi:10.1016/j.cattod.2004.03.016.

[16] R.M. Contractor, H.E. Bergna, H.S. Horowitz, C.M. Blackstone, B. Malone, C.C. Torardi, B. Griffiths, U. Chowdhry, A.W. Sleight, Butane oxidation to maleic anhydride over vanadium phosphate catalysts, Catal. Today. 1 (1987) 49-58. doi:10.1016/09205861(87)80026-3.

[17] L. Neal, S. Yusuf, J. Sofranko, F. Li, Alkali-doped manganese oxides as redox catalysts for oxidative dehydrogenation of ethane, in: 249th Natl. Meet. Am.-Chem.-Soc. ACS, (2015)

[18] L. Neal, S. Yusuf, J. Sofranko, F. Li, Oxidative Dehydrogenation of Ethane: A Chemical Looping Approach, Energy Technol. (2016) doi:10.1002/ente.201600074. (In Press)

[19] P. Cho, T. Mattisson, A. Lyngfelt, Comparison of iron-, nickel-, copper- and manganesebased oxygen carriers for chemical-looping combustion, Fuel. 83 (2004) 1215-1225. doi:10.1016/j.fuel.2003.11.013.

[20] J. Adánez, L.F. de Diego, F. García-Labiano, P. Gayán, A. Abad, J.M. Palacios, Selection of Oxygen Carriers for Chemical-Looping Combustion, Energy Fuels. 18 (2004) 371-377. doi:10.1021/ef0301452.

[21] Z.-Y. Tian, P. Mountapmbeme Kouotou, N. Bahlawane, P.H. Tchoua Ngamou, Synthesis of the Catalytically Active $\mathrm{Mn}_{3} \mathrm{O}_{4}$ Spinel and Its Thermal Properties, J. Phys. Chem. C. 117 (2013) 6218-6224. doi:10.1021/jp312444s.

[22] R. Schefflan, Teach Yourself the Basics of Aspen Plus, American Institute of Chemical Engineers, Hoboken, NJ, USA, 2011.

http://site.ebrary.com/lib/alltitles/docDetail.action?docID=10447807 (accessed November 29, 2015). 
[23] A.J. Kidnay, W.R. Parrish, Fundamentals of Natural Gas Processing, CRC Press, 2006.

[24] G.T. Rochelle, Amine Scrubbing for $\mathrm{C}_{2}$ Capture, Science. 325 (2009) 1652-1654.

[25] M. Yan, Simulation and optimization of an ethylene plant, Texas Tech University, 2000. https://ttu-ir.tdl.org/ttu-ir/handle/2346/16119 (accessed November 29, 2015).

[26] M. Ball, A. Basile, T.N. Veziroglu, Compendium of Hydrogen Energy: Hydrogen Use, Safety and the Hydrogen Economy, Woodhead Publishing, 2015.

[27] G.C. Battiston, L. Dalloro, G.R. Tauszik, Performance and aging of catalysts for the selective hydrogenation of acetylene: a micropilot-plant study, Appl. Catal. 2 (1982) 1-17. doi:10.1016/0166-9834(82)80170-X.

[28] S. Hall, Rules of Thumb for Chemical Engineers (5th Edition), Elsevier, 2012

[29] M.A. Fox, J.K. Whitesell, Organic Chemistry, Jones \& Bartlett Learning, 2004.

[30] G. Hassan, M. Pourkashanian, D. Ingham, L. Ma, P. Newman, A. Odedra, Predictions of $\mathrm{CO}$ and NOx emissions from steam cracking furnaces using GRI2.11 detailed reaction mechanism - A CFD investigation, Comput. Chem. Eng. 58 (2013) 68-83. doi:10.1016/j.compchemeng.2013.06.011.

[31] L.-S. Fan, Chemical Looping Systems for Fossil Energy Conversions, John Wiley \& Sons, 2011. 


\section{Figures}

\begin{tabular}{|c|c|}
\hline Figure \# & Image size (column fitting) \\
\hline 1 & 1.5 \\
\hline 2 & 1.5 \\
\hline 3 & 1 \\
\hline 4 & 1 \\
\hline 5 & 1 \\
\hline 6 & 1 \\
\hline 7 & 1 \\
\hline 8 & 1 \\
\hline 9 & 1 \\
\hline 10 & 1 \\
\hline 11 & 1 \\
\hline
\end{tabular}




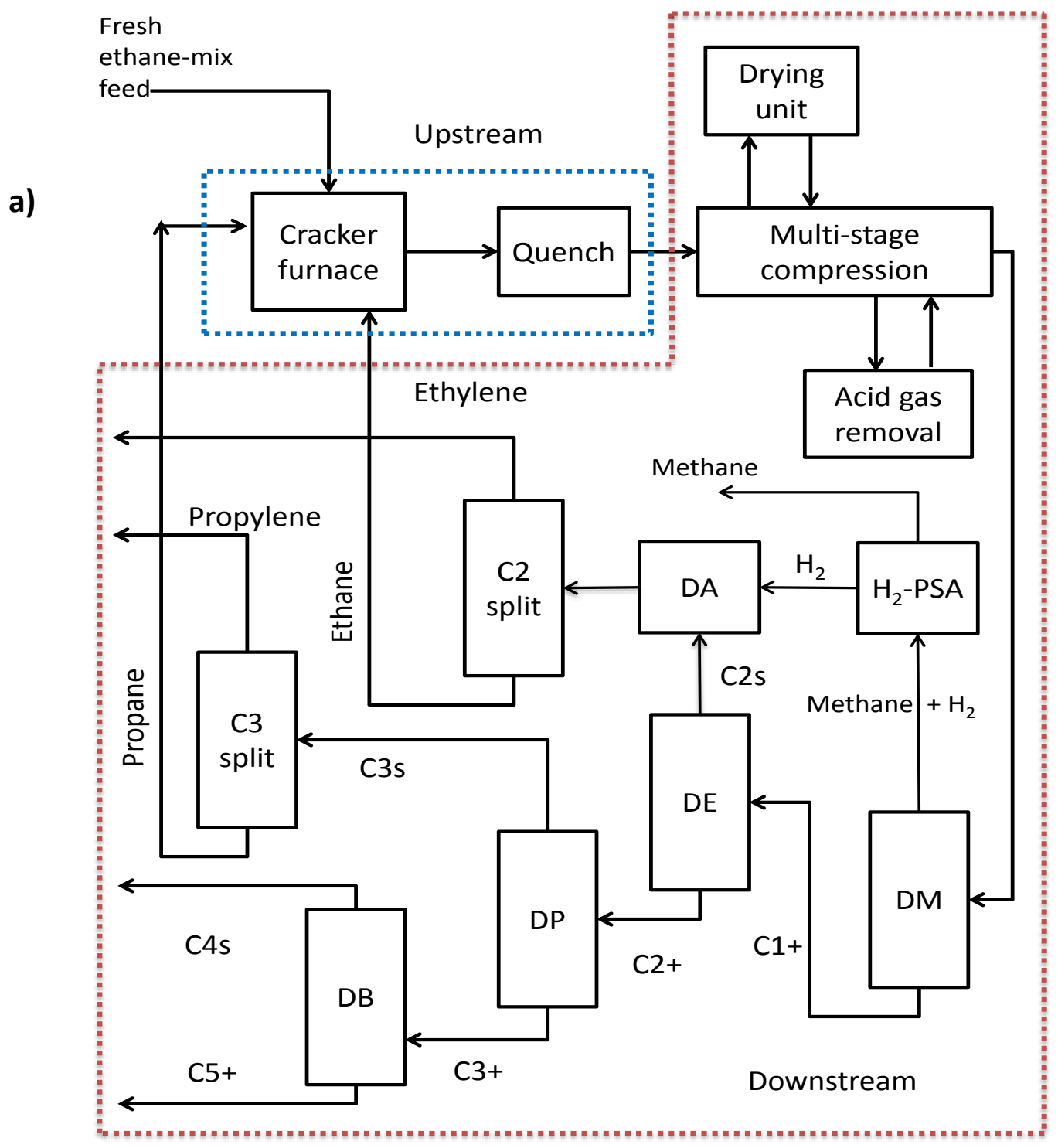




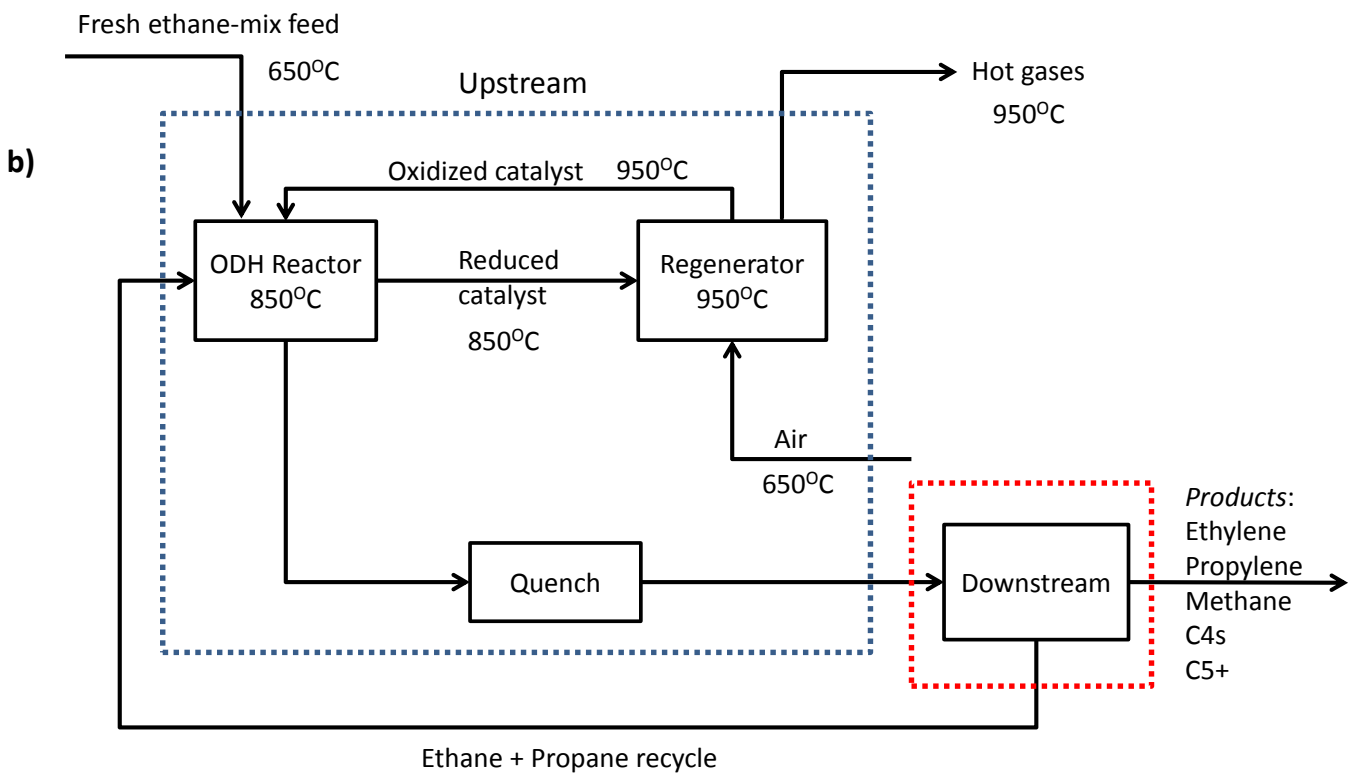

Figure 1: a) Simplified process flow diagram of ethane cracking process [DM: Demethanizer, DA: Deacetylenizer, DE: Deethanizer, DP: Depropanizer, DB: Debutanizer, C2 split: C2-splitter, C3 split: C3-splitter, PSA: Pressure Swing Adsorption] b) Simplified schematic of the cyclic redox ODH (CL-ODH) process (temperatures for key units and streams are listed for the reference case)

a)

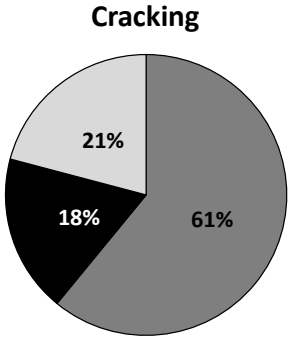

$677 \mathrm{MW}$ (thermal)

a Overall energy demand neglecting the available energy from the quench, regenerator and the exit hot air from regenerator

b)

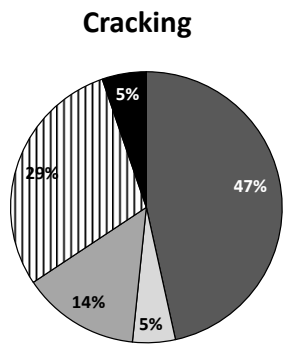

264.5 MW (thermal)
ODH reference

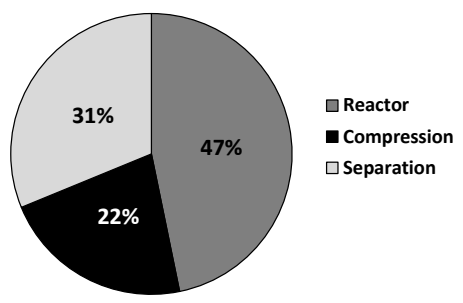

$380 \mathrm{MW}$ (thermal) ${ }^{\mathrm{a}}$

ODH reference

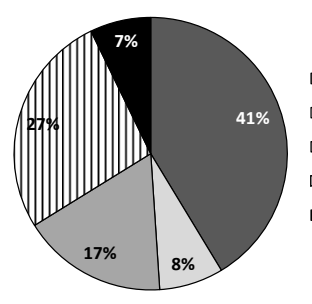

口Compression

$\square$ Demethanizer (DM)

$\square$ C2-splitter

$\square$ Refrigeration of DM feed

- Others

Figure 2: a) Section wise energy distribution and b) overall energy distribution for a steam cracking process 


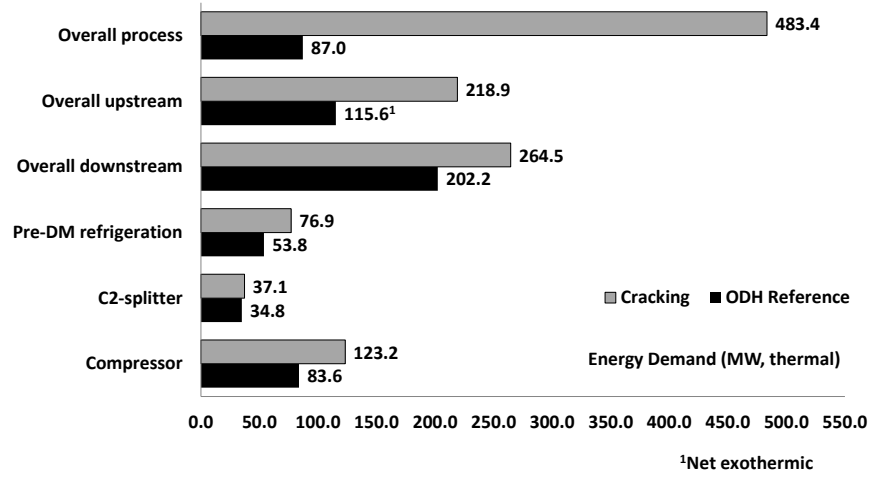

Figure 3: Comparison of the energy distributions

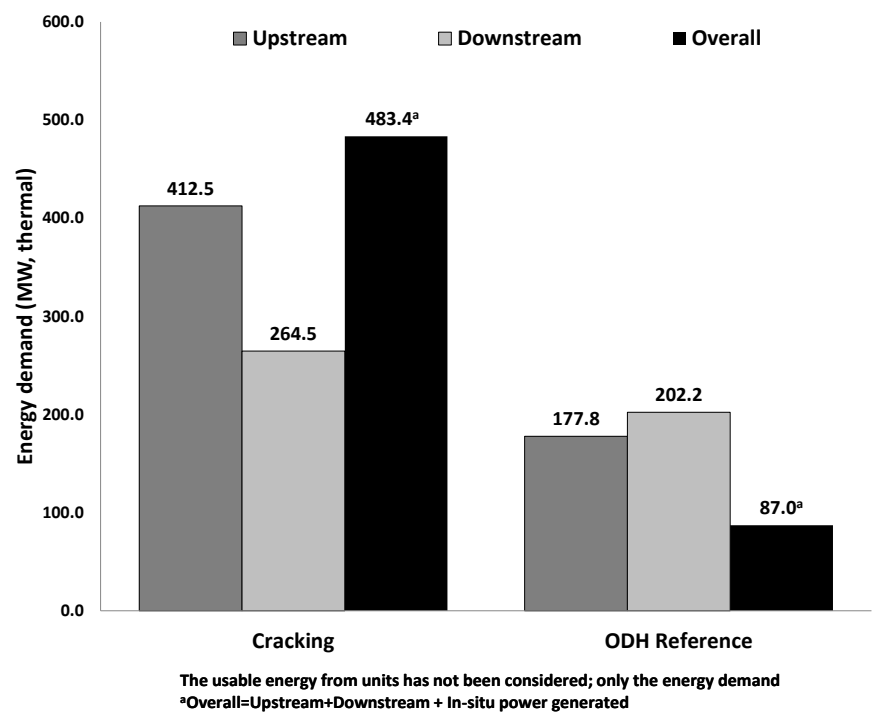

Figure 4: Relative energy demand (section wise and overall) 


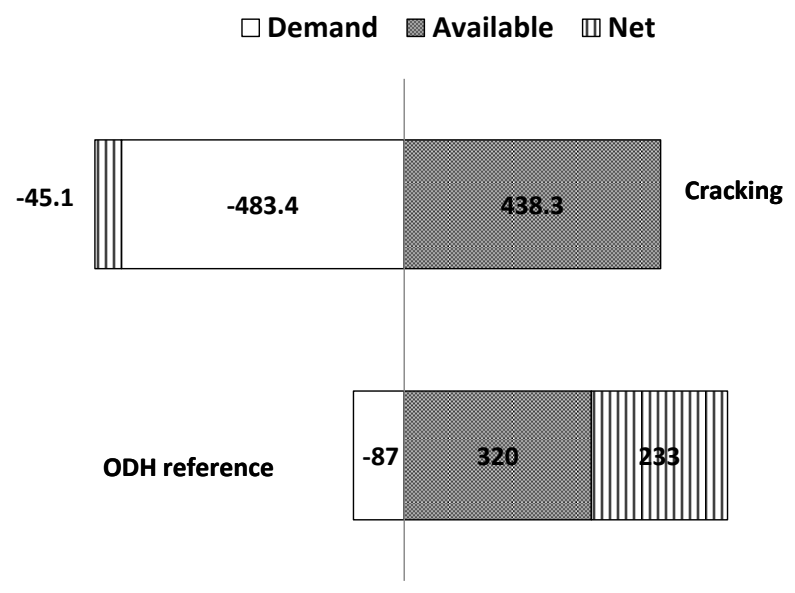

Figure 5: (Thermal) Energy surplus and emissions

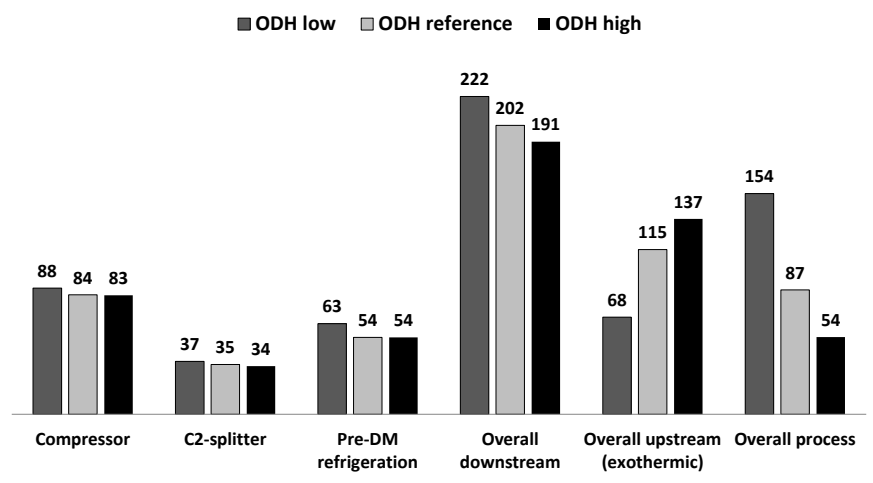

Figure 6: Thermal energy $\left(\mathrm{MW}_{\text {th }}\right)$ comparison for the ethane ODH cases

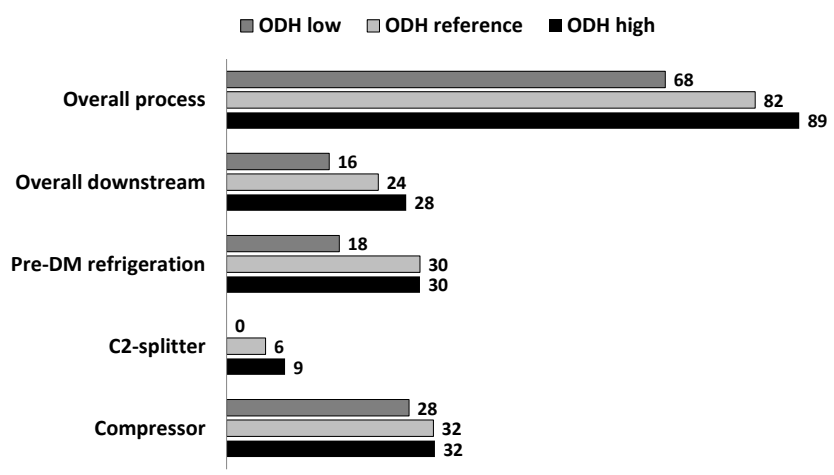

Figure 7: \% Reduction in the energy demand 


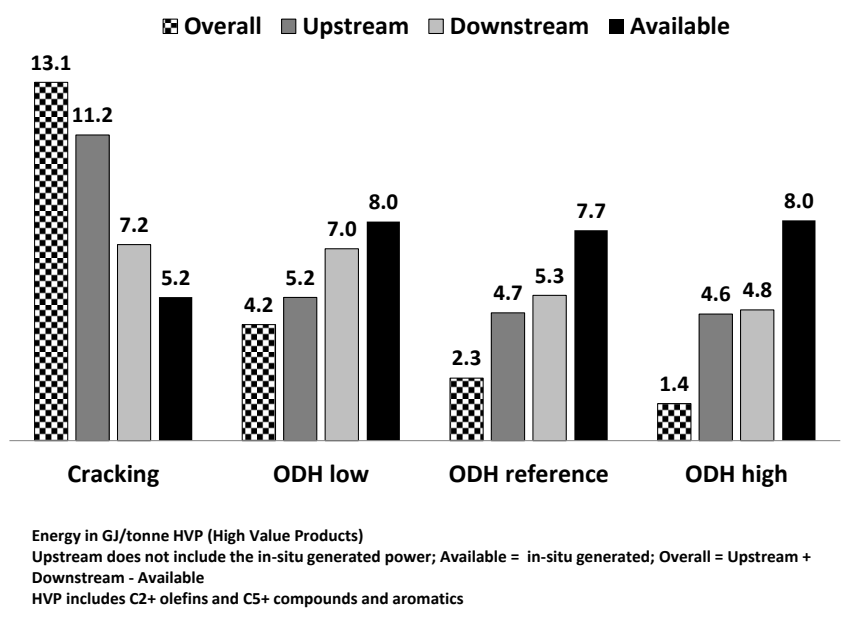

Figure 8: Thermal energy distribution comparison

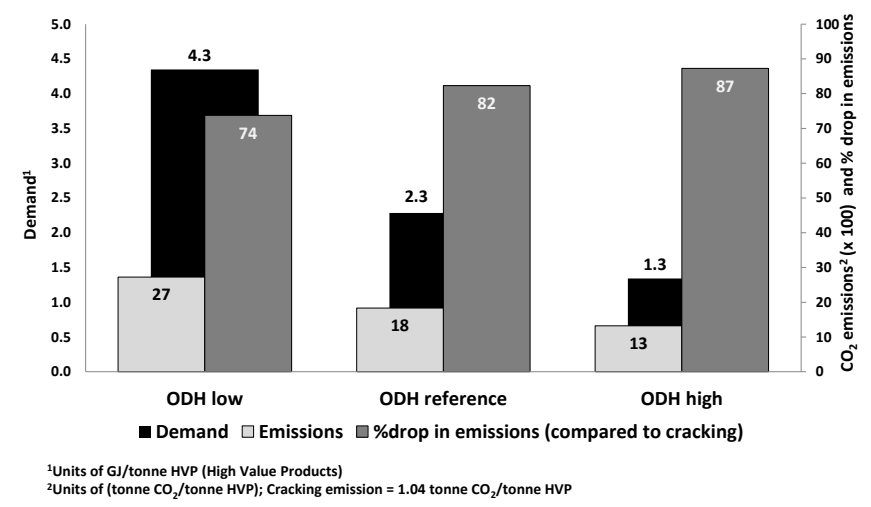

Figure 9: Thermal energy demand and emission comparison 


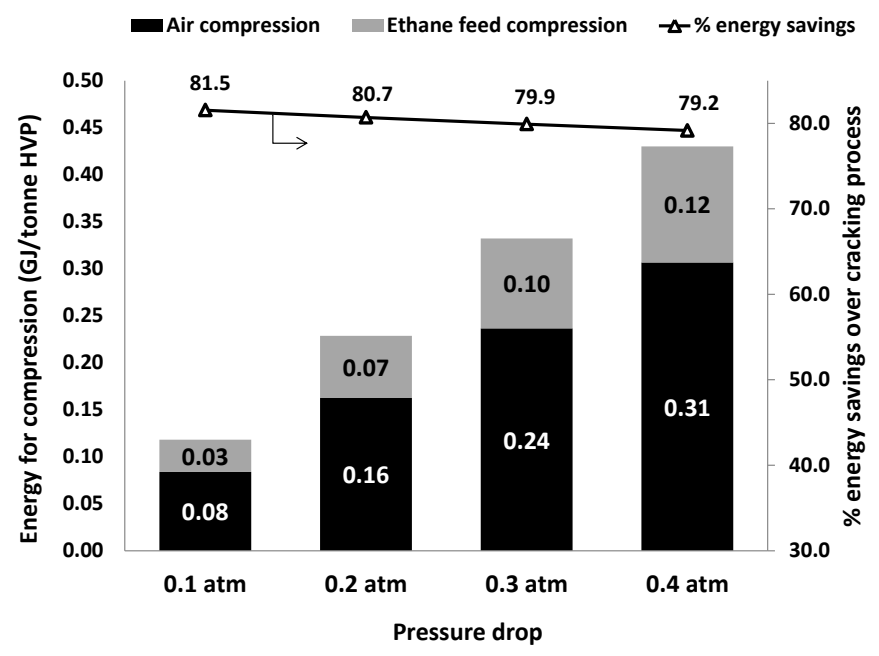

Figure 10: Effect of pressure drop

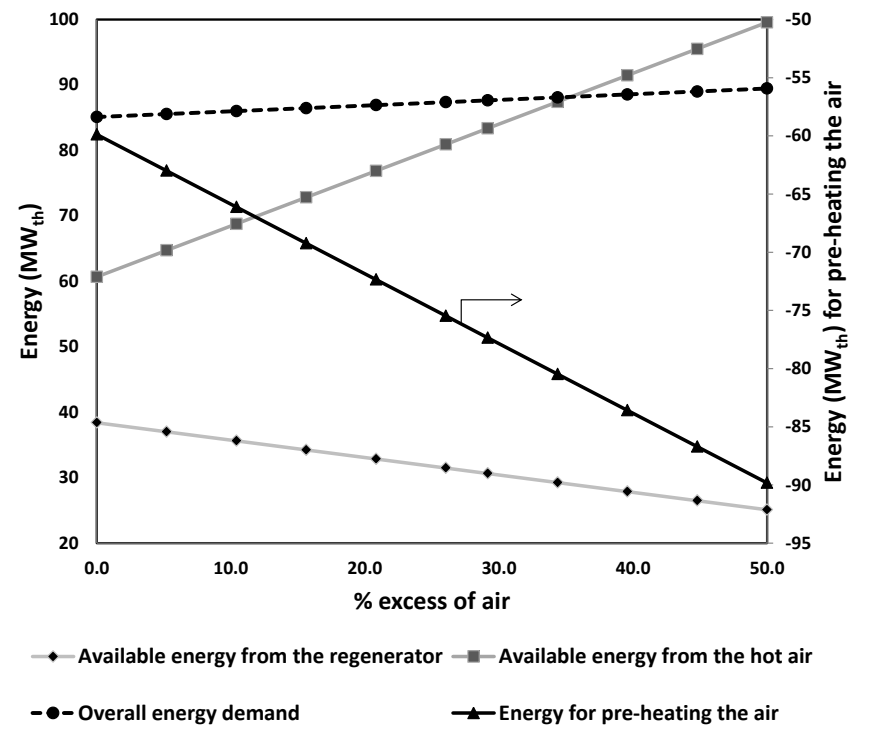

Figure 11: Effect of excess air on the thermal energy demand $\left(\mathrm{MW}_{\text {th }}\right)$ 


\section{$\underline{\text { Tables }}$}

Table 1: ASPEN Plus ${ }^{\circledR}$ modules, property methods and databanks

\begin{tabular}{|l|l|}
\hline Stream class & MIXCISLD \\
\hline Databank & $\begin{array}{l}\text { PURE, AQUEOUS, SOLIDS, } \\
\text { INORGANIC }\end{array}$ \\
\hline Solid components & $\mathrm{Mn}_{3} \mathrm{O}_{4}, \mathrm{MnO}, \mathrm{MgO}$ \\
\hline Property method & $\begin{array}{l}\mathrm{PR}-\mathrm{BM} \text { and STEAM -TA for steam } \\
\text { cycles }\end{array}$ \\
\hline \multicolumn{2}{|c|}{ Unit operation models } \\
\hline Regenerator, Reducer and Deacetylenizer & RStoic \\
\hline Pressure changers & MCompr \\
\hline Heat exchangers & Heater \\
\hline Distillation columns & DSTWU \\
\hline Separators/Flash columns & Sep/Flash2 \\
\hline
\end{tabular}

Table 2: Carbon yield for the two cases

\begin{tabular}{|c|c|c|}
\hline & Case I: Cracker & Case II: ODH reference \\
\hline Ethane conversion & $65 \%$ & $85 \%$ \\
\hline \multicolumn{3}{|c|}{ Carbon yield (\%) } \\
\hline Ethane & $35.0 \%$ & $15.0 \%$ \\
\hline Methane & $3.4 \%$ & $6.0 \%$ \\
\hline Acetylene & $0.5 \%$ & $0.2 \%$ \\
\hline Ethylene & $56.1 \%$ & $65.0 \%$ \\
\hline Propylene & $1.2 \%$ & $2.4 \%$ \\
\hline Propane & $0.1 \%$ & $0.3 \%$ \\
\hline Butadiene & $2.1 \%$ & $2.4 \%$ \\
\hline Butenes & $0.2 \%$ & $2.4 \%$ \\
\hline Butanes & $0.2 \%$ & $0.0 \%$ \\
\hline $\mathrm{C}_{5}$ 's & $0.6 \%$ & $0.5 \%$ \\
\hline Benzene & $0.5 \%$ & $2.4 \%$ \\
\hline Toluene & $0.1 \%$ & $0.5 \%$ \\
\hline $\mathrm{CO}^{\mid}$ & $0.0 \%$ & $1.5 \%$ \\
\hline $\mathrm{CO}_{2}$ & $0.0 \%$ & $1.5 \%$ \\
\hline
\end{tabular}


Table 3: Simulation conditions and assumptions

\begin{tabular}{|l|l|}
\hline Ambient condition & $\mathrm{T}=25^{\circ} \mathrm{C}, \mathrm{P}=1 \mathrm{~atm}$ \\
\hline Reaction assumptions & $\begin{array}{l}\text { As per the carbon yield distribution in } \\
\text { Table 2 }\end{array}$ \\
\hline Heat loss in chemical looping reactors & $1 \%$ of the total thermal output \\
\hline Chemical looping reactor operating pressure & $1 \mathrm{~atm}$ \\
\hline Deacetylenizer operating pressure & 42 atm \\
\hline Compressor specifications & $\begin{array}{l}4 \text { stage with intercooler at } 25^{\circ} \mathrm{C} \\
\text { Isentropic efficiency of } 0.72\end{array}$ \\
\hline Air feed (to the regenerator) & $10 \%$ excess \\
\hline Discharge temperatures to the environment & Temperature: $25^{\circ} \mathrm{C}$ \\
\hline Thermal energy to steam efficiency & $85 \%$ \\
\hline Thermal energy to electric energy efficiency & $40 \%$ \\
\hline
\end{tabular}

Table 4: Column details [25]

\begin{tabular}{|c|c|c|c|c|c|c|c|c|}
\hline \multirow[b]{2}{*}{ Unit } & \multicolumn{4}{|c|}{ Key component recoveries } & \multirow{2}{*}{$\begin{array}{l}\text { Reflux } \\
\text { ratio }\end{array}$} & \multicolumn{2}{|c|}{ Pressure (bar) } & \\
\hline & Light key & Recovery & Heavy key & Recovery & & $\begin{array}{c}\text { Condens } \\
\text { er }\end{array}$ & Reboiler & \\
\hline Demethanizer & Methane & $99.90 \%$ & Ethylene & $0.50 \%$ & 3 & 26 & 27 & \multirow{6}{*}{$\begin{array}{c}\text { Partial } \\
\text { condenser } \\
\text { with all } \\
\text { vapor } \\
\text { distillate }\end{array}$} \\
\hline Deethanizer & Ethylene & $99.99 \%$ & Propane & $0.10 \%$ & 0.6 & 10 & 11 & \\
\hline Depropanizer & Propylene & $99.99 \%$ & Iso-butylene & $1.40 \%$ & 4.6 & 10 & 11 & \\
\hline C2-splitter & Ethylene & $99.00 \%$ & Ethane & $0.06 \%$ & 2.7 & 4 & 11 & \\
\hline C3-splitter & Propylene & $99.60 \%$ & Propane & $0.24 \%$ & 18 & 16 & 18 & \\
\hline Debutanizer & Iso-butane & $99.90 \%$ & Butadiene & $0.10 \%$ & 8.6 & 4 & 5 & \\
\hline
\end{tabular}

Table 5: Choice of refrigerant [28]

\begin{tabular}{|c|c|c|}
\hline \multirow{2}{*}{ Unit } & T required & \multirow{2}{*}{ Refrigerant } \\
\cline { 2 - 3 } & deg C & \\
\hline Demethanizer & -95 & Ethylene \\
\hline Deethanizer & -43 & Ethane \\
\hline C2 splitter & -76.3 & Ethane \\
\hline Fractionation & -110 & Ethylene \\
\hline Depropanizer & 25 & Propylene \\
\hline C3 splitter & 34 & Propylene \\
\hline Debutanizer & 32 & Propylene \\
\hline
\end{tabular}


Table 6: Exit gas and solid streams

\begin{tabular}{|c|c|c|}
\hline \multicolumn{3}{|c|}{ Mole flow $(\mathrm{kmol} / \mathrm{hr})$} \\
\hline & Cracking (Case I) & ODH reference (Case II) \\
\hline \multicolumn{3}{|c|}{ Feed } \\
\hline Ethane & 4807.0 & 5353.3 \\
\hline Methane & 126.5 & 140.9 \\
\hline Propane & 126.5 & 140.9 \\
\hline Total & 5060.0 & 5635.0 \\
\hline Steam & 2500 & NA \\
\hline $\begin{array}{c}\text { Final ethylene output (after } \\
\text { the downstream } \\
\text { purification) }\end{array}$ & \multicolumn{2}{|c|}{4077} \\
\hline \multicolumn{3}{|c|}{ Output from Cracker or ODH reactor } \\
\hline Ethane & 2580.4 & 943.1 \\
\hline Methane & 704.2 & 894.9 \\
\hline Acetylene & 74.5 & 14.0 \\
\hline Ethylene & 4242.1 & 4163.9 \\
\hline Propylene & 82.6 & 140.6 \\
\hline Propane & 19.5 & 60.9 \\
\hline Butadiene & 80.5 & 74.8 \\
\hline Butenes & 7.5 & 75.8 \\
\hline Butanes & 15.6 & 1.1 \\
\hline Pentanes & 19.9 & 12.6 \\
\hline Benzene & 14.0 & 49.8 \\
\hline Toluene & 2.4 & 9.0 \\
\hline $\mathrm{CO}_{2}$ & 0.0 & 279.2 \\
\hline $\mathrm{CO}$ & 0.0 & 279.2 \\
\hline $\mathrm{H}_{2}$ & 4441.9 & 1616.6 \\
\hline $\mathrm{H}_{2} \mathrm{O}$ & 2497.9 & 3918.4 \\
\hline Total Flow (kmol/hr) & 14782.9 & 12533.9 \\
\hline Total Flow (kg/hr) & 276549.0 & 276442.0 \\
\hline \multicolumn{3}{|c|}{ Solid stream flowrates and compositions (Case II) } \\
\hline & Solids in & Solids out \\
\hline Temperature $\left({ }^{\circ} \mathrm{C}\right)$ & 950 & 850 \\
\hline Pressure (atm) & 1 & 1 \\
\hline & million $\mathrm{kg} / \mathrm{hr}$ & million $\mathrm{kg} / \mathrm{hr}$ \\
\hline
\end{tabular}




\begin{tabular}{|c|c|c|c|c|}
$\mathrm{Mn}_{3} \mathrm{O}_{4}$ & 1.26 & 20.82 & 0.17 & 2.85 \\
\hline $\mathrm{MnO}$ & 0 & 0 & 1.01 & 16.96 \\
\hline $\mathrm{MgO}$ & 4.79 & 79.18 & 4.79 & 80.19 \\
\hline
\end{tabular}

Table 7: Comparison of the energy consumption

\begin{tabular}{|c|c|c|c|}
\hline \multicolumn{4}{|c|}{ Comparison } \\
\hline & & Cracking & ODH reference \\
\hline \multicolumn{2}{|c|}{ Ethane conversion } & 65.0 & 85.0 \\
\hline \multirow{2}{*}{ Flow (tonne/hr) } & Ethylene & 114.2 & 114.2 \\
\hline & Fresh Feed & 152.2 & 168.8 \\
\hline \multirow{9}{*}{ Upstream $\left(\mathrm{MW}_{\mathrm{th}}\right)$} & Reactor (Endothermicity) & 235.9 & 0.0 \\
\hline & Regenerator $^{1}$ & $\mathrm{n} / \mathrm{a}$ & -33.2 \\
\hline & Ethane recycle & 50.0 & 18.6 \\
\hline & Propane recycle & 1.2 & 1.2 \\
\hline & Feed pretreatment & 77.9 & 86.0 \\
\hline & Steam heat & 47.6 & $\mathrm{n} / \mathrm{a}$ \\
\hline & Air preheat & $\mathrm{n} / \mathrm{a}$ & 72.0 \\
\hline & Exit gas cool ${ }^{1}$ & $\mathrm{n} / \mathrm{a}$ & -76.1 \\
\hline & Quench $^{1}$ & -193.6 & -183.7 \\
\hline \multirow{11}{*}{$\begin{array}{c}\text { Downstream }{ }^{2} \\
\left(\mathrm{MW}_{\mathrm{th}}\right)\end{array}$} & Compressor & 123.2 & 83.6 \\
\hline & Demethanizer & 13.5 & 15.4 \\
\hline & Deethanizer & 5.4 & 2.7 \\
\hline & Depropanizer & 1.2 & 1.2 \\
\hline & C2-splitter & 37.1 & 34.8 \\
\hline & C3-splitter & 1.2 & 2.4 \\
\hline & Debutanizer & 0.0 & 0.1 \\
\hline & Deacetylenizer & 5.5 & 4.6 \\
\hline & $\mathrm{CO}_{2}$ scrubbing & 0.0 & 3.4 \\
\hline & PSA & 0.7 & 0.2 \\
\hline & Fractionation & 76.9 & 53.8 \\
\hline \multicolumn{2}{|c|}{ Upstream Subtotal $\left(\mathrm{MW}_{\text {th }}\right)$} & 218.9 & -115.2 \\
\hline \multicolumn{2}{|c|}{ Downstream Subtotal $\left(\mathrm{MW}_{\mathrm{th}}\right)$} & 264.5 & 202.2 \\
\hline \multicolumn{2}{|c|}{$\operatorname{Net}\left(\mathrm{MW}_{\mathrm{th}}\right)$} & 483.4 & 87.0 \\
\hline \multicolumn{2}{|c|}{ Net $\left(\mathrm{GJ}_{\mathrm{th}} /\right.$ tonne ethylene $)$} & 15.2 & 2.7 \\
\hline \multicolumn{4}{|c|}{$\begin{array}{l}{ }^{1} \text { Steam energy from thermal with } 85 \% \text { conversion } \\
{ }^{2} \text { Converted to thermal assuming } 40 \% \text { conversion }\end{array}$} \\
\hline
\end{tabular}


Table 8: $\Delta \mathrm{H}_{\text {reaction }}$ and molar flow rate of the fuel

\begin{tabular}{|c|c|c|}
\hline \multicolumn{3}{|c|}{ Heat release (LHV) } \\
\hline $\mathrm{CO}+\frac{1}{2} \mathrm{O}_{2} \rightarrow \mathrm{CO}_{2}$ & 282 & $\mathrm{~kJ} / \mathrm{mole}$ \\
\hline $\mathrm{CH}_{4}+2 \mathrm{O}_{2} \rightarrow \mathrm{CO}_{2}+2 \mathrm{H}_{2} \mathrm{O}$ & 800 & $\mathrm{~kJ} / \mathrm{mole}$ \\
\hline $\mathrm{H}_{2}+\frac{1}{2} \mathrm{O}_{2} \rightarrow \mathrm{H}_{2} \mathrm{O}$ & 239 & $\mathrm{~kJ} / \mathrm{mole}$ \\
\hline \multicolumn{3}{|c|}{ Molar flowrate (kmol/hr) } \\
\hline $\mathrm{CO}$ & Cracking & $\mathrm{ODH}$ \\
\hline $\mathrm{CH}_{4}$ & 0 & 279.1 \\
\hline $\mathrm{H}_{2}$ & 703.8 & 894.0 \\
\hline \multicolumn{2}{|c|}{} \\
\hline
\end{tabular}

Table 9: Carbon yield for the different ethane ODH cases considered

\begin{tabular}{|c|c|c|c|}
\hline \multicolumn{4}{|c|}{ \%Carbon yield } \\
\hline Component & Case III & Case II & Case IV \\
\hline & ODH low & ODH reference & ODH high \\
\hline Ethane conversion & $66 \%$ & $85 \%$ & $90 \%$ \\
\hline Ethane & $34.10 \%$ & $15.00 \%$ & $10.00 \%$ \\
\hline Methane & $3.30 \%$ & $6.00 \%$ & $7.00 \%$ \\
\hline Acetylene & $0.50 \%$ & $0.19 \%$ & $0.19 \%$ \\
\hline Ethylene & $56.10 \%$ & $65.00 \%$ & $65.03 \%$ \\
\hline Propylene & $1.20 \%$ & $2.38 \%$ & $2.50 \%$ \\
\hline Propane & $0.10 \%$ & $0.25 \%$ & $0.25 \%$ \\
\hline Butadiene & $2.10 \%$ & $2.38 \%$ & $2.50 \%$ \\
\hline Butenes & $0.20 \%$ & $2.38 \%$ & $2.50 \%$ \\
\hline Butanes & $0.20 \%$ & $0.03 \%$ & $0.03 \%$ \\
\hline $\mathrm{C}_{5}$ 's & $0.60 \%$ & $0.50 \%$ & $0.80 \%$ \\
\hline Benzene & $0.50 \%$ & $2.38 \%$ & $5.00 \%$ \\
\hline Toluene & $0.10 \%$ & $0.50 \%$ & $1.00 \%$ \\
\hline $\mathrm{CO}$ & $0.50 \%$ & $1.50 \%$ & $1.60 \%$ \\
\hline $\mathrm{CO}_{2}$ & $0.50 \%$ & $1.50 \%$ & $1.60 \%$ \\
\hline
\end{tabular}

Table 10: Exit gas composition of the ethane ODH cases

\begin{tabular}{|l|c|c|c|}
\hline \multicolumn{4}{|c|}{ Mole flow (kmol/hr) } \\
\hline & Case III & Case II & Case IV \\
\hline
\end{tabular}




\begin{tabular}{|c|c|c|c|}
\hline \multicolumn{4}{|c|}{ Feed } \\
\hline Ethane & 4774.7 & 5353.3 & 5606.9 \\
\hline Methane & 125.65 & 140.9 & 147.6 \\
\hline Propane & 125.65 & 140.9 & 147.6 \\
\hline Total & 5026 & 5635.0 & 5902.0 \\
\hline $\begin{array}{l}\text { Final ethylene output (after } \\
\text { the downstream purification) }\end{array}$ & \multicolumn{3}{|c|}{4077} \\
\hline \multicolumn{4}{|c|}{ Output } \\
\hline Ethane & 2457.1 & 943.1 & 691.7 \\
\hline Methane & 601.2 & 894.9 & 902.2 \\
\hline Acetylene & 42.3 & 14.0 & 14.0 \\
\hline Ethylene & 4111.6 & 4163.9 & 4172.5 \\
\hline Propylene & 92.8 & 140.6 & 147.5 \\
\hline Propane & 48.2 & 60.9 & 63.1 \\
\hline Butadiene & 75.7 & 74.8 & 78.6 \\
\hline Butenes & 7.3 & 75.8 & 79.7 \\
\hline Butanes & 10.1 & 1.1 & 1.1 \\
\hline Pentanes & 17.3 & 12.6 & 20.1 \\
\hline Benzene & 12.0 & 49.8 & 104.8 \\
\hline Toluene & 2.1 & 9.0 & 18.0 \\
\hline $\mathrm{CO}$ & 150.2 & 279.2 & 295.9 \\
\hline $\mathrm{CO}_{2}$ & 150.2 & 279.2 & 295.9 \\
\hline $\mathrm{H}_{2}$ & 1411.3 & 1616.6 & 1703.3 \\
\hline $\mathrm{H}_{2} \mathrm{O}$ & 3417.1 & 3918.4 & 4315.9 \\
\hline Total Flow (kmol/hr) & 12606.5 & 12533.9 & 12904.3 \\
\hline Total Flow (kmol/hr)(Dry) & 9189.4 & 8635.5 & 8588.4 \\
\hline Total Flow (kg/hr) & 288697.0 & 276442.0 & 284259.0 \\
\hline Total Flow (kg/hr) (Dry) & 227189.2 & 205910.8 & 206572.8 \\
\hline
\end{tabular}

